\title{
Disproportionate reduction in tryptic response to endogenous compared with exogenous stimulation in chronic pancreatitis
}

\author{
J M BRAGANZA, J J RAO
}

British Medical fournal, 1978, 2, 392-394

\section{Summary and conclusions}

The secretin-pancreozymin (SP) and Lundh-Borgström (meal) tests were compared in diagnosing chronic pancreatitis $(\mathrm{CP})$. A range of normal values for each test was obtained in a control group of 22 patients without pancreatic disease. Seventeen patients with $\mathrm{CP}$ were given the tests on separate days. The peak concentration of bicarbonate after secretin was reduced in 14 of these 17 patients, post-secretin bicarbonate output fell in 13, while peak tryptic activity (PTA) in duodenal juice after pancreozymin was below normal in 10; the overall incidence of abnormal results in SP tests was $88 \%$. The mean tryptic activity (MTA) in a two-hour collection of duodenal juice after the test meal was reduced below normal in 16 of the 17 patients.

In the control group PTA after pancreozymin was closely similar to MTA after the test meal, but in the patients with CP MTA was significantly less than PTA. PTA and MTA correlated significantly in both the control and $C P$ groups, and the slopes of the two regression lines were not significantly different. In each patient with $\mathrm{CP}$ the tryptic response to the test meal was only a third of the tryptic response to intravenous pancreozymin. This disproportionate reduction in tryptic response to endogenous compared with exogenous stimulation in CP accounts for the high success rate of the meal test, which equalled the SP test.

The Lundh-Borgström test is a sensitive indicator of $C P$ and is within the resources of most hospitals. The SP test is better suited to specialist centres and may provide valuable additional information in individual cases.

\section{Introduction}

Secretin-pancreozymin ${ }^{1}$ and Lundh-Borgström² tests are commonly used to evaluate pancreatic function, yet there is little information on their relative usefulness in diagnosing pancreatic disease. A comparative assessment of these tests has been in progress since June 1975 in a centre with special interest in pancreatic disease. We report the results in chronic pancreatitis $(\mathrm{CP})$.

\section{Patients and methods}

Of the 39 patients investigated, 22 served as controls and 17 were patients with CP. The control group comprised three volunteers and 19 patients in whom from all available information, including laparotomy in 12, the pancreas was considered to be normal. In the 17 patients with CP the diagnosis was established from characteristic

University Department of Gastroenterology, Royal Infirmary, Manchester M13 9WL

J M BRAGANZA, MSC, MRCP, lecturer

J J RAO, MD, research fellow

histological changes in surgically resected specimens (two patients) $\frac{\bar{y}}{\bar{x}}$ radiological detection of pancreatic calculi (eight), or the triad of diabetes, steatorrhoea, and relapses of pancreatitis (four). In addition three young patients with documented relapses of pancreatitis startinges in their 20 s showed impaired glucose tolerance, and in each case the typical morphological changes of CP were detected by ultrasonography $^{3}$ and computerised tomography. ${ }^{4}$

Every patient was given a secretin pancreozymin (SP) test and Lundh-Borgström (meal) test on separate days. Tests were performedŌ as described ${ }^{12}$ and their order was randomised. In the SP test intra-3. venous injection of 2 units of secretin (Boots) per $\mathrm{kg}$ was followedin 30 minutes later by intravenous injection of 2 units of pancreozyming (Boots) per kg, duodenal juice being aspirated in 10-minute fractions $\overrightarrow{+}$ for 30 minutes after each injection. The concentration of bicarbonate was measured by back titration; tryptic activity was determined by a $\mathrm{pH}$-stat method using $p$-toluene sulphonyl arginine methyl ester as substrate. ${ }^{5}$ In the Lundh-Borgström test, after the patient had ingested ${ }^{5}$ $500 \mathrm{ml}$ of the standard meal a pooled two-hour collection of duodenal juice was obtained and the tryptic activity in this sample determined.

Statistical-We used logarithmic values for bicarbonate and enzyme analyses since the skew distribution of these variables in the population $\stackrel{5}{?}$ may be normalised by logarithmic transformation. ${ }^{6-8}$ Secretory $\vec{\theta}$ responses in the control and CP groups were compared by Student's $t$ tests, while in each group differences in duodenal juice tryptic ${ }^{\circ}$ activity after stimulation by intravenous pancreozymin and the test meal were evaluated with paired $t$ tests. Standard tests of correlation, linearity, and parallelism were then applied to the tryptic data. ${ }^{9}$

\section{Results}

$S P$ test-Figure 1 shows the mean values and lower limits of normal for peak concentration of bicarbonate after secretin (control mean $94.1 \mathrm{mmol}(\mathrm{mEq}) / 1$; mean $-2 \mathrm{SD} 57.5 \mathrm{mmol} / \mathrm{l})$, output of bicarbonate in 30 minutes after secretin (control mean $9.26 \mathrm{mmol}$; mean-2SD $5.78 \mathrm{mmol}$ ), and peak tryptic activity (PTA) after pancreozymin (control mean $51.6 \mathrm{IU} / \mathrm{ml}$; mean-2 SD $26.4 \mathrm{IU} / \mathrm{ml}$ ). ㅇ Secretion of bicarbonate and trypsin was significantly less in the 3 . CP group than in the controls. The peak concentration of bicarbonate after secretin was reduced in $14(82 \%)$ of the 17 patients with CP; a O fall in post-secretin bicarbonate output occurred in $13(76 \%)$, while

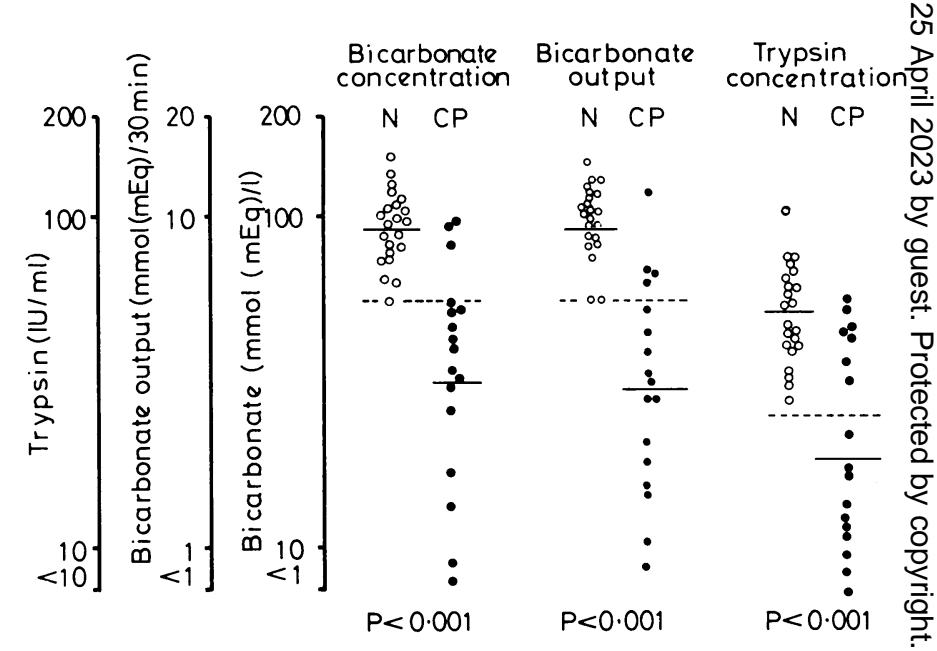

FIG 1 -Results of SP test in 22 normal controls $(\mathrm{N})$ and 17 patients with chronic pancreatitis (CP). Solid bars represent mean values. Dashed bars represent lower limits of normal ranges (mean-2 SD). Groups compared with $t$ tests. 
PTA was abnormally low in $10(59 \%)$. Overall the SP test gave an abnormal result in $15(88 \%)$ of the 17 patients with CP.

Meal test-Figure 2 shows the mean values (control mean 53.2 $\mathrm{IU} / \mathrm{ml}$ ) and lower limit of normal (mean-2 SD $23.6 \mathrm{IU} / \mathrm{ml}$ ) for mean tryptic activity (MTA) after the meal test. The mean tryptic response in patients with CP was significantly less than in the control group $(\mathrm{P}<0.001)$. MTA was reduced in $16(94 \%)$ of the 17 patients.

\section{COMPARISON OF RESPONSES TO SP AND MEAL TESTS}

In both control and CP groups there was little correlation between the post-secretin peak bicarbonate concentration and MTA after the

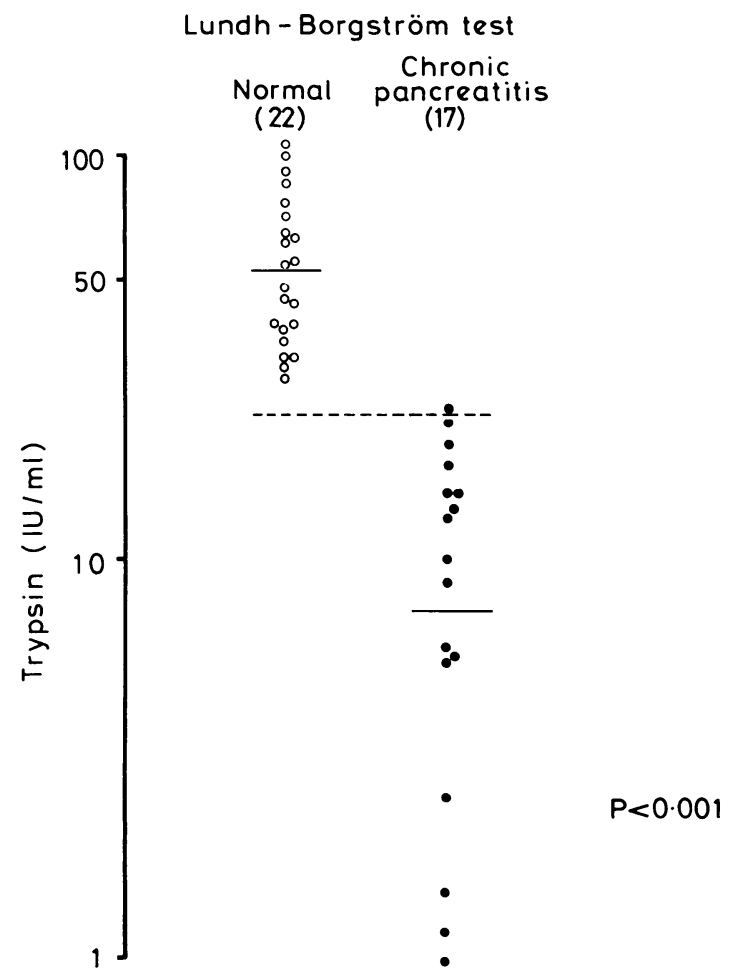

FIG 2-Results of meal tests. Solid bars representmeans. Dashed bar represents lower limit of normal range (mean-2 SD). Groups compared with $t$ test.

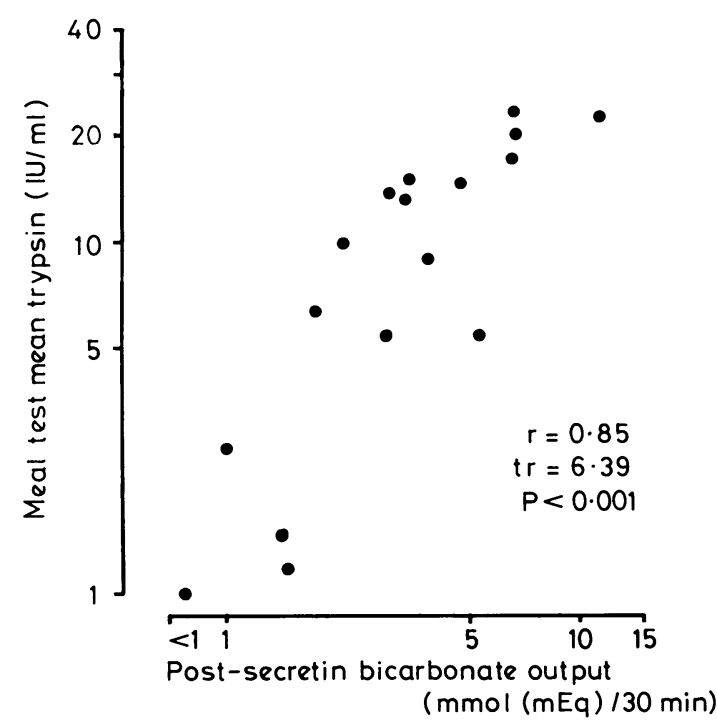

FIG 3-Correlation between post-secretin bicarbonate output and trypsin response to meal in 17 patients with chronic pancreatitis. test meal (controls $r=0 \cdot 14$; CP group $r=0 \cdot 42$ ). A significant correlation was found, however, between post-secretin output of bicarbonate and postprandial MTA, particularly in the patients with CP ( $r=$ $0 \cdot 85$ - fig 3). In the control group PTA after intravenous pancreozymin $(51.6 \mathrm{IU} / \mathrm{ml})$ was closely similar to MTA after the test meal $(53.2 \mathrm{IU} / \mathrm{ml})(P>0.95)$, but in the CP group MTA in response to the meal was significantly less than PTA in response to intravenous pancreozymin $(\mathrm{P}<0.001)$. Correlation and regression coefficients relating PTA and MTA were significant in both controls and CP groups (see fig 4), and the slopes of the two regression lines were not significantly different ( $F$ test $: P>0.05$ ). Thus for an assigned value for PTA of, say, 25 the corresponding MTA was similar (30) when the pancreas was normal (fig 4) but only one-third of the expected result $(9 \cdot 6)$ in patients with CP. The best approximation of the ratio of trypsin response to endogenous stimulation by a test meal in the patients with CP compared with the controls proved to be $30 \%$, with $95 \%$ confidence intervals of $20-50 \%$ (fig 4 ).

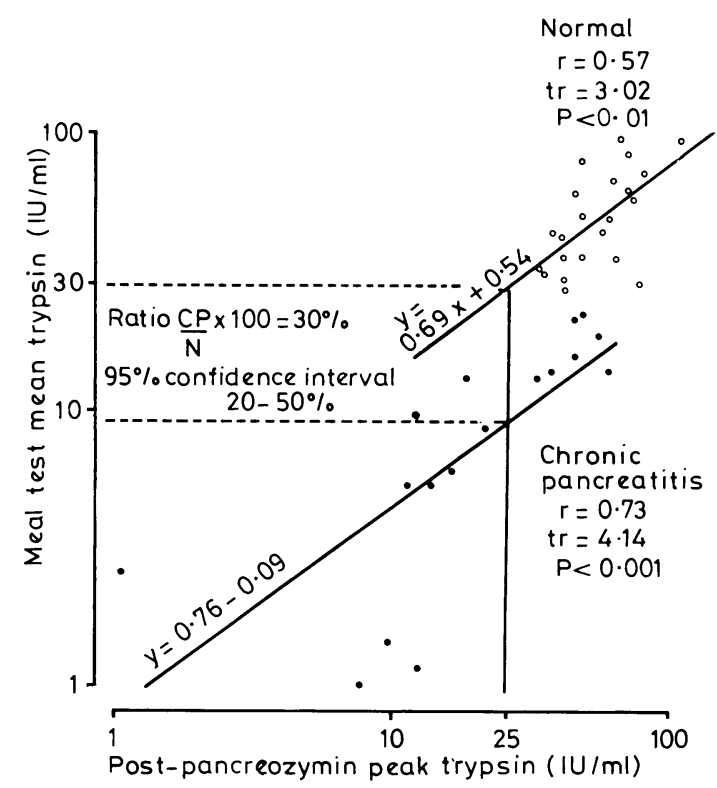

FIG 4-Relation between PTA and MTA in normal controls $(\mathrm{N})$, and patients with chronic pancreatitis (CP), and extrapolated values for MTA in control and $\mathrm{CP}$ groups for assigned value of 25 for PTA.

\section{Discussion}

James $^{10}$ dismissed existing comparative studies between Lundh and secretin or secretin-pancreozymin tests as "few and rather unsatisfactory." Reports before 1973 were difficult to evaluate: in two studies the stimulants were given in tandem, ${ }^{112}$ while in two others ${ }^{13} 14$ patients with chronic pancreatitis and acute pancreatitis were grouped together, although these are now known to be different entities. ${ }^{15}$

Gyr et $a l^{16}$ and Waller ${ }^{17}$ independently reported that the secretin test (bicarbonate response) and meal test (tryptic response) were equally sensitive in detecting pancreatic dysfunction in CP. Their results seemed to be at variance with observations that in $\mathrm{CP}$ reduction in bicarbonate secretion is the characteristic feature, ${ }^{1819}$ and occurs earlier in the disease ${ }^{20}$ than reduction in pancreatic enzyme secretion.

Our findings (fig 3) corroborate the results of Gyr et al and Waller and show that the high success rate of the meal test in chronic pancreatitis was due to a disproportionate reduction in tryptic response to endogenous compared with exogenous stimulation of the pancreas (fig 4). This finding was fortuitous, for the anomalous reduction in MTA compared with PTA in the CP group was detected only because MTA was closely similar to PTA in the controls. These results differ from those of Worning, ${ }^{21}$ in which the regression lines relating mean postprandial concentration of amylase in duodenal juice and total output of amylase secreted in response to simultaneous intra- 
venous infusion of secretin and pancreozymin were identical in normal people and patients with pancreatic disease. The studies were not strictly comparable, however: Worning measured amylase but not trypsin; assessed enzyme responses to a combined infusion of two different secretin and two different pancreozymin preparations rather than to pancreozymin alone; compared the output of enzyme after exogenous stimulation with the concentration of enzyme after a meal rather than using the same criterion for both tests; and included several different disease entities in the pancreatic malfunction group rather than restricting the consideration to patients with $\mathrm{CP}$ alone.

MTA in duodenal juice after a test meal depends not only on the amount of cholecystokinin-pancreozymin released from the intestinal mucosa but also on dilution of pancreatic enzymes by gastric, biliary, and intestinal secretions. Until these other factors have been carefully assessed the disproportionate reduction in tryptic response to endogenous compared with exogenous cholecystokinin-pancreozymin should not be taken to imply impairment of release of this hormone in CP. Whatever the explanation for this unreported phenomenon our observations validate the practical clinical usefulness of the Lundh-Borgström test (which is within the resources of most hospitals) when a diagnosis of CP is suspected. The SP test, which is better suited to specialist centres, provides valuable additional information about gall-bladder function and the presence of obstruction in pancreatic or biliary ducts ${ }^{18}$ and ideally will still be required for a more complete appraisal in individual cases.

This work was supported in part by a grant from the Research Grants Committee of the Central District, Manchester Area Health Authority (Teaching). We thank Professor H T Howat and Dr R
Holmes for permission to investigate patients under their care; Miss P Hine and Mr G H Kay for expert technical help; Mr A C C Gibbs, of the department of community medicine, University of Manchester, for statistical advice; and Dr R Ollerenshaw, department of medical illustration, for the figures. We are indebted to Professor $\mathrm{H} T$ Howat $\mathrm{T}$ for critical appraisal of the manuscript.

\section{References}

${ }^{1}$ Burton, P, et al, Gut, 1960, 1, 111.

${ }^{2}$ Lundh, G, and Borgström, B, Ciba Foundation Symposium on Exocrine Pancreas. London, Churchill, 1972.

${ }^{3}$ Russell, J G B, et al, Gut, In press.

${ }^{4}$ Fawcitt, R A, et al, British fournal of Radiology, 1978, 51, 1.

${ }^{5}$ Haverback, B J, et al, American fournal of Medicine, 1960, 29, 424

${ }^{6}$ Sarles, H, et al, Gastroenterologia, 1963, 99, 279.

7 Sun, D C H, Gastroenterology, 1963, 45, 203.

Arinciples of Biological Assay. Liseases, 1963, 13, 123. Hall, 1948.

${ }^{10}$ James, O, Gut, 1973, 14, 582.

${ }^{11}$ Zieve, L, et al, American fournal of Digestive Diseases, 1966, 11, 685.

${ }^{12}$ Hartley, R C, et al, American fournal of Digestive Diseases, 1966, 11, 27.

${ }^{13}$ Moeller, D D, Dunn, C D, and Klotz, A P, American fournal of Digestive i Diseases, 1972, 17, 799 .

${ }_{14}^{14}$ Lurie, B, et al, Scandinavian fournal of Gastroenterology, 1973, 8, 27.

${ }^{15}$ Sarles, H, Bibliotheca Gastroenterologica, 1965, 7, 7.

${ }^{16} \mathrm{Gyr}, \mathrm{K}$, et al, American fournal of Digestive Diseases, 1975, 20, 506.

17 Waller, S L, Gut, 1975, 16, 657.

${ }^{18}$ Howat, H T, fournal of the Royal College of Physicians, 1968, 3, 85.

19 Wormsley, K G, British fournal of Clinical Practice, 1970, 24, 271.

${ }^{20}$ Dreiling, D A, and Janowitz, H D, Ciba Foundation Symposium on Exocrine Pancreas. London, Churchill, 1962.

${ }^{21}$ Worning, H, Scandinavian fournal of Gastroenterology, 1971, 6, 257.

(Accepted 25 May 1978)

\title{
Corticosteroids and liver amoebiasis
}

\author{
P C STUIVER, TH J L M GOUD
}

British Medical fournal, 1978, 2, 394-395

\section{Summary and conclusions}

Patients with amoebiasis who receive steroid treatment may suffer adverse affects including acute amoebic dysentery and exacerbation of the amoebiasis. In some cases the presenting symptoms are initially misdiagnosed and steroids prescribed, which provokes fulminating progression of hepatic amoebiasis. Repeated stool examinations often yield negative results.

Any patient being considered for treatment with corticosteroids who has lived in the tropics should be investigated for amoebiasis serologically and by repeated stool examination. Even after negative results the possibility of amoebiasis should be reconsidered if diarrhoea or fever develops during or after steroid treatment.

\section{Introduction}

One of the lesser-known complications of high-dose corticosteroid treatment is the superimposition of parasitic infections. ${ }^{1}$

\footnotetext{
Department of Tropical Medicine, Havenziekenhuis, Rotterdam, The Netherlands

P C STUIVER, MD, consultant physician

TH J L M GOUD, MD, consultant physician
}

Steroid treatment is hazardous and may be disastrous, particularly in patients with amoebiasis. The adverse effects of corticosteroids in amoebic colitis have been documented, though only sporadically. ${ }^{2-7}$ The question arises whether deaths are more common than is generally realised, since patients with "colitis" are, rightly or wrongly, often treated with corticosteroids at some stage. Probably even in patients who pass amoebic cysts but are asymptomatic steroids applied locally or systemically may precipitate acute amoebic dysentery. ${ }^{6}$

The hazards of corticosteroids in amoebiasis, however, are not limited to the colon. The following cases show the risk of fulminating progression of hepatic amoebiasis during treatment with corticosteroids.

\section{Case histories}

CASE 1

A 26-year-old German sailor was treated in Portugal with prednisone, $20 \mathrm{mg}$, daily, for pain in the right shoulder. On arrival in Rotterdam 10 days later his condition had worsened considerably. $\mathrm{He}$ had severe bloody diarrhoea and had lost $10 \mathrm{~kg}$ in weight, and the pain in his shoulder was worse. He was extremely ill, with a high fever. At physical examination tenderness was noted below the right costal margin, but there were no other abnormalities. Erythrocyte sedimentation rate (ESR) was $84 \mathrm{~mm}$ in the first hour and white cell count (WBC) $21.4 \times 10^{\circ} / 1\left(21400 / \mathrm{mm}^{3}\right)$ with $17 \%$ band forms. Results of liver function tests and chest radiograms were normal. Vegetative forms of Entamoeba histolytica were found in the stools. On a liver scan a large defect was seen in the right lobe. An amoebic abscess of the liver was diagnosed. At aspiration of the abscess $200 \mathrm{ml}$ of brownish, 